\title{
The Mediating Influence of Leadership Behaviour on the Relationship between Organizational Health and Work Engagement
}

\author{
Tatheera Begum, Kennedy Andrew Thomas* \\ Department of Education, Christ University, Bangalore, India
}

Received November 12, 2019; Revised January 19, 2020; Accepted February 7, 2020

Copyright $\odot 2020$ by authors, all rights reserved. Authors agree that this article remains permanently open access under the terms of the Creative Commons Attribution License 4.0 International License

\begin{abstract}
Efficient leadership and a healthy teaching environment are the two factors that determine how school teachers conduct themselves professionally. Work engagement not only reflects the teachers' performance but also implies the performance of the pupils and the school and it depends on how congenial their working conditions are. The present study intended to assess the extent to which the leadership behaviour of principals mediated the effect of organizational health on the work engagement of 516 secondary school teachers working in Bengaluru, India. The organizational health inventory was employed to quantify the organizational health of schools at institutional, managerial and technical levels, the Utrecht tool was used to measure teachers' work engagement through their vigor, dedication and absorption, and the leadership behaviour of principals was measured in terms of consideration and initiating behaviour. The findings implied a positive relationship between organizational health and teachers' work engagement. Further, while leadership behaviour indeed mediated the impact of organizational health on work engagement, the mediating effect was only partial. The results imply that the teachers' work engagement cannot be entirely attributed to the school management and working conditions, which implies scope for further research on the factors affecting work engagement among the teachers.
\end{abstract}

Keywords Organizational Health, Leadership Behaviour, Work Engagement, Pupil Performance, Mediating Effect

\section{Introduction}

The roles of school administrators have witnessed significant changes in this century and leadership endeavor has become much more apparent in recent years (Buluc,
2015). Efficient school leaders empower teachers and contribute significantly to school improvement (Muijs \& Harris, 2006). On the other hand, healthy individuals grow in healthy settings and schools are among the healthy settings where an individual develops. Schools need to remain a healthy organization to operate more effectively and satisfy its stakeholders. Healthy organizations can provide a positive environment and instill common values in their staff; thereby accomplish their mission (Hoy \& Tarter, 1997). Hence, the organizational health of a school system is important not only to realize the development of school but also to foster effective student educational outcomes and teacher work outcomes (Stolp, 1994; Freiberg, 2005). The study analyzes the impact of organizational health on the work engagement of teachers and how it has been mediated by the leadership behaviour of principals.

\subsection{Organizational Health}

According to Miles (1969), organizational health can be defined as "one that not only survives in its environment, but continues to cope adequately over the long haul, and continuously develops and expands its coping abilities" (p.378). Miles (1969)'s configuration of a healthy organization reflects the task needs, maintenance needs, as well as the growth and development needs of a social system. However, it was impossible to operationalize Miles's formu lation of organizational health. Hence, Parson et al.'s (1953) perspective of organizational health was adopted.

According to Parson et al. (1953) and Etzioni (1975), any social system must be able to solve four basic problems such as adaptation, goal attainment, integration, and latency. They suggested that schools have three levels of control over these problems: technical level, managerial level and institutional level (Hoy, Tarter \& Bliss, 1990; Savas \& Karakus, 2012). The technical level of organizational health 
is more concerned with the process of teaching and learning. It involves finding solutions to problems that are related to teaching and learning effectively (Freiberg, 2005). The managerial level of organizational health is concerned with the internal administration of the organization. It involves acquiring all the necessary resources for teaching, which includes financial, personnel and physical materials by the school administrative officers. At this level, the schools must identify practices that can enhance teacher's loyalty, trust, commitment, and motivation (Savas, \& Karakus, 2012). The institutional level of organizational health connects the school with its environment. It represents the amount of support received by the school from its community. Administrators and teachers can perform their functions effectively if they are protected from undue pressures from individuals and groups outside the school (Freiberg, 2005).

Hoy, Tarter, and Kottkamp (1991) identified a set of seven dimensions of organizational health to represent the three Parsonian organizational levels and the four functional problems of social systems. The dimensions include Institutional integrity (Institutional level); Principal influence, Consideration, In itiating structure, Resource allocation (Managerial level); and Morale and Academic emphas is (Technical level). These dimensions are described as follows: "Institutional Integrity (II) describes a school that has integrity in its educational program and can cope successfully with destructive outside forces; Initiating Structure (IS) refers to the principal's task- and achievement -oriented behaviour; Consideration (CO) is principal behaviour that is friendly, supportive, and collegial. The principal looks out for the welfare of faculty members and is open to their suggestions; Principal Influence (PI) is the principal's ability to affect the actions of superiors; Resource Support (RS) refers to a school where adequate classroom supplies and instructional materials are available and extra materials are easily obtained; Morale (MO) is the sense of trust, confidence, enthusiasm, and friendliness among teachers; and Academic Emphasis (AC) refers to the school's press for achievement including high but achievable goals set for students, orderly and serious learning environment, and hardworking atmosphere among students" (Hoy, Tarter, and Kottkamp, 1991, p.186).

Parson's concept of organizational health was put to practical use by Hoy and Fedman (1987) who developed a reliable and valid set of measures known as Organizational Health Inventory (OHI) for measuring the various aspects of organizational health. The same has been adopted in the study to measure organizational health of schools".

\subsection{Leadership Behaviour}

Leadership has been considered as an important factor in effective schools and numerous studies have been carried out on the same. Principal's leadership behaviour plays an important role in creating a positive school culture and learning environment. Principals must possess certain competencies and styles to be successful in their organization which calls for the need to test a list of skills and other indicators of competence among principals. Existing theory and research on leadership reveals that leadership can be conceptualized to support two distinct categories, namely interpersonal activities and task achievement. Accordingly, two separate dimensions have been proposed by Halpin and Winer (1957), Initiating structure and Consideration. "Initiating Structure refers to the leader's behaviour in delineating the relationship between himself and members of the work-group, and in endeavoring to establish well-defined patterns or organization, channels of communication, and methods of procedure. Consideration refers to behaviour indicative of friendship, mutual trust, respect, and warmth in the relationship between the leader and the members of his staff' (Halpin, 1956, p.4). Thus, the Initiating structure is oriented and consideration is more concerned with group cohesiveness and morale. These two kinds of leadership were considered to be independent and incompatible in measuring leadership qualities and provide a strong frame work for studying leadership in schools (Kunz \& Hoy, 1976; Evenson, 1959).

\subsection{Work Engagement}

Employees who are engaged are likely to work harder through increased discretionary effort when compared to disengaged employees. The concept of work engagement was first theorized by Kahn (1990) who stated that employees who are cognitively, physically and emotionally connected with their work roles can be described as engaged employees. According to him, engaged teachers projected a unique identity that was different from their identity as a result of their attachment towards their job. Later, Bakker, Schaufeli, Leiter, and Taris (2008) posited that work engagement can be defined as a "positive and motivating state of work-related subjective well-being." It points to the personal interest of teachers towards their work and the resultant enjoyment and satisfaction derived from work (van Beek, Hu, Schaufeli, Taris, et al., 2012).

In spite of the various definitions available for work engagement, the study adopted the most often cited definition provided by Schaufeli and Bakker (2003), which is "work engagement can be defined as an active, positive work-re lated state that is characterized by vigor, dedication, and absorption". Vigor refers to the willingness of the employee to invest effort in his/ her work as well as persistence in the work at times of difficulties. In short, vigor is characterized by employee's energy levels and mental resilience towards work (Schaufeli, Salanova, Gon zalez-Ro ma \& Bakker, 2002). Dedication, on the other hand, refers to employee's involvement in work while experiencing a sense of enthusiasm, pride, inspiration, 
significance, and challenge (Bakker, 2011). The last defining factor absorption, is characterized by being completely engrossed in work with full concentration, whereby one finds it hard to detach oneself from work (Hakanen, Bakker \& Schaufeli, 2006).

Several job resources and physical resources have been found to play an important role in predicting the work engagement of employees (Albrecht, 2010; Schaufeli, Bakker \& Van Rhenen, 2009; Hakanen, Perhoniemi, \& Toppinen-Tanner, 2008; Hobfoll, Johnson, Ennis \& Jackson, 2003). The present study investigates the role of organizational health in determining work engagement among teachers.

\subsection{Research Gaps}

Recently, the number of studies about work engagement has increased significantly due to its impact on individual and organizational outcomes. In spite of several studies carried out on the drivers of work engagement of teachers (Guglielmi, Bruni, Simbula, Fraccaroli, et al., 2016; Albrecht, 2010; Schaufeli, Bakker \& Van Rhenen, 2009), there is a paucity of research in exploring the impact of organizational health on work engagement. Further, among the studies that discuss the relationship between organizational factors and work engagement, most of them have studied factors like organizational commitment, support, trust, organizational culture and climate (Wang, Liu, Zou, Hao, et al., 2017; Nazir \& Islam, 2017; Roslan, Ho, Ng \& Sambasivan, 2015). The few studies based on organizational health also tested satisfaction and commitment of teachers but not work engagement (Dou, Devos \& Valcke, 2017; Aldridge \& Fraser, 2016; Fernet, Trépanier, Austin \& Levesque-Côté, 2016). Further, the influence of the principal's leadership behaviour on organizational health (Garcia, 2018; Allen, Grigsby, \& Peters, 2015; Korkmaz, 2007) has been studied extensively but not on work engagement. The mediating influence of leadership behaviour between organizational health and work engagement has not been explored previously.

\subsection{A Conceptual Framework for the Study}

According to Hoy \& Woolfolk (1993), all social systems must meet four main needs to sustain and evolve. These include successfully coping with the environment, maintaining harmony and coordination within the system, achieving goals, and maintaining and transmitting distinctive culture and values. Schools have control over these needs at three levels, namely technical, managerial, and institutional level (Parsons, 1951, 1967). Further, school health is defined as the ability of a school to pursue its mission of educating students by aligning these three levels of control to meet the aforementioned needs of a social system (Hoy, Tarter, \& Kottkamp, 1991). Hence, in the present study, the organizational health of schools was measured at these three levels. The technical level is concerned with producing educated students through a teaching-learning process. Teachers who like each other and help each other feel a sense of accomplishment and promote harmony (morale) and those who believe in a student's ability create achievable goals for students and provide with an orderly learning environment (academic emphasis). Hence at the technical level, school health has been operationalized using two constructs, namely Morale and Academic emphasis. The managerial level deals with the internal administrative functions of the school, with principals as the prime administrative officers. The principals must be able to influence the actions of the superiors (Principal influence), be friendly and supportive with a genuine concern for the welfare of teachers (Consideration), and provide with all the necessary classroom supplies and instructional materials (Resource support) to coordinate work-effort. Hence, the managerial level has been operationalized using factors, namely Principal influence, Initiating structure, Consideration, and Resource support. Lastly, the institutional level is concerned with integrating the school with the environment and hence has been operationalized using the factor 'Institutional integrity' which refers to protecting teachers from unwanted demands from the community so that its educational integrity is maintained as it copes with its environment. Organizational health has been conceptualized in the study as an assessment tool to assess the health of the school at technical, managerial and institutional levels.

The leadership behavior of principals could be adequately described as using two main factors or behaviors: Consideration and Initiating structure (Korman, 1966). While Consideration refers to the extent to which the principal is likely to have job relationships characterized by trust, respect for subordinates' opinions and consideration for their feelings, Initiating structure refers to the extent to which the principals define their role and those of their subordinates' towards achieving a common goal (Fle is hman $\&$ Peters, 1962). The three dimensions of Work engagement (Vigor, Dedication, and Absorption) proposed by Schaufeli et al. and Bakker (2003) was adopted in the study. Further, perceptions of organizational health were positively correlated with teachers' outcomes (Viseu, Rus, \& de Jesus, 2015; Mehta, Atkins, \& Frazier, 2013). The present study intends to explore the effects of school health on teacher's work engagement through the principal's leadership behavior.

Hypothesis 1: Leadership behaviour mediates the relationship between organizational health and work engagement. 


\section{Methodology}

\subsection{Study Design and Sample}

A Descriptive survey design was adopted for the study and data were collected with the help of standardized questionnaires. A Stratified random sampling technique was used for selecting the study participants. The sample composed of 516 secondary school teachers from aided, unaided and government schools in Bangalore. The study data was collected during the period from Jan-2017 to Jun-2017.

\subsection{Research Instrument and Data Analysis}

Respondents' work engagement was measured using the Utrecht work engagement scale, which has three subscales reflecting the underlying dimensions of work engagement: vigor (6 items), dedication (5 items) and absorption (6 items), provided by Schaufeli and Bakker (2003). The scale has been validated in several countries (Xanthopoulou, Bakker, Demerouti \& Kantas, 2007; Yi-wen \& Yi-qun, 2005; Storm \& Rothmann, 2003); hence, has been used in our study. Organizational health inventory (44 items) (Hoy, Tarter \& Kottkamp, 1991; Hoy \& Fedman, 1987) was used for measuring the organizational health at three levels with six dimensions: Institutional level (Institutional integrity), Managerial level (Principal influence, Consideration, Resource support) and Technical level (Morale and Academic emphasis). The Principal's leadership behaviour was measured using two factors, Consideration and Initiating structure. The scales measuring Consideration $(\alpha=0.842)$ and Initiating behaviour $(\alpha=0.804)$ were found to be internally consistent and reliable and hence were adopted in the study. The mediation analysis was carried out with the help of PROCESS macro available in Statistical Package for Social Sciences (SPSS) v24.

\section{Results}

\subsection{Sample Characteristics}

The sample consisted of male and female in equal proportion (50\%), out of which, around $67 \%$ of them were above 30 years of age. Concerning the type of institution in which the participant teachers work (aided, unaided or government schools), it was found that they were equally distributed $(33.3 \%)$. Though a majority of the participants $(80 \%)$ had less than 20 years of experience, more than half of them (57\%) reported holding a Post Graduate degree.
Table 1. Sample description

\begin{tabular}{|l|c|c|}
\hline Factor & Frequency & Percentage \\
\hline Age group (years) & 86 & 16.67 \\
\hline 21 to 30 & 170 & 32.95 \\
\hline 31 to 40 & 180 & 34.88 \\
\hline 41 to 50 & 80 & 15.5 \\
\hline$>51$ & 258 & 50.00 \\
\hline Gender & 258 & 50.00 \\
\hline Female & \multicolumn{2}{|l}{} \\
\hline Male & 172 & 33.30 \\
\hline Type of institution & 172 & 33.30 \\
\hline Aided & 172 & 33.30 \\
\hline Unaided & \multicolumn{2}{|l}{} \\
\hline Govt. & 75 & 14.50 \\
\hline Work experience (years) & 120 & 23.30 \\
\hline$<5$ & 216 & 41.90 \\
\hline$<10$ & 105 & 20.30 \\
\hline$<20$ & 296 & 57.40 \\
\hline$>20$ & 220 & 42.60 \\
\hline Educational qualification & \multicolumn{2}{|l}{} \\
\hline Post Graduate & \multicolumn{2}{|l|}{} \\
\hline Under Graduate & \multicolumn{2}{|l|}{} \\
\hline
\end{tabular}

\subsection{Mediating Effects of Leadership Behaviour}

Mediation analysis was conducted with the help of Hayes and Preacher process method to find out whether leadership behaviour (LB) has any mediating influence on the relationship between organizational health $(\mathrm{OHI})$ and work engagement (WE)or not.

Results showed that organizational health is a significant predictor of leadership behaviour of principal $(\mathrm{R}=0.398$; $\mathrm{R} 2=0.159 ; \mathrm{F}(1,514)=97.051)$ with $\beta=-0.527, \mathrm{SE}=0.053$, $\mathrm{p}<0.05$ [a path] and also leadership behaviour was found to be a significant predictor of work engagement with $\beta=-0.386, \mathrm{SE}=0.055, \mathrm{p}<0.05$ [b path]. The direct effect of organizational health on work engagement [c' path] $(\beta=0.434, \mathrm{SE}=0.072, \mathrm{p}<0.05)$ and the indirect effect through mediation by leadership behaviour [c path] $(\beta=0.203$, $\mathrm{SE}=0.036$, LLCI $=0.137$, ULCI $=0.281$ ) was found to be significant at $5 \%$ level. Hence, the variable leadership behaviour acts as a partial mediator between organizational health and work engagement. Therefore, the hypothesis "Leadership behaviour plays a major role between organizational health and work engagement" has been partially accepted. 
Table 2. Mediation analysis through leadership behaviour as the mediator

\begin{tabular}{|l|c|c|c|c|c|c|}
\hline Regression paths & $\mathbf{B}$ & $\mathbf{S . E}$ & $\mathbf{t}$ & $\mathbf{p}$ & LLCI & ULCI \\
\hline OHI on LB & -0.527 & 0.053 & -9.851 & $0.000^{*}$ & -0.633 & -0.422 \\
\hline LB on WE & -0.386 & 0.055 & -7.053 & $0.000^{*}$ & -0.493 & -0.278 \\
\hline Direct effect, OHI on WE & 0.434 & 0.072 & 6.000 & $0.000^{*}$ & 0.292 & 0.576 \\
\hline $\begin{array}{l}\text { Indirect effect (OHI on WE } \\
\text { including LB as mediator) }\end{array}$ & 0.203 & 0.036 & & & 0.137 & 0.281 \\
\hline Total effect & 0.637 & 0.069 & 9.182 & $0.000^{*}$ & 0.501 & 0.774 \\
\hline
\end{tabular}

SE-St andard error, LLCI-Lower Limit Confidence Interval, ULCL-Upper Limit Confidence Limit. Indirect effects weretested using the boot strapping procedure with 5000 bootstrap samples

* supported

Table 3. $\mathrm{R}^{2}$ values of the variables

\begin{tabular}{|l|c|c|c|c|c|c|c|}
\hline & R & R-sq & MSE & F & df1 & df2 & P \\
\hline OHI --> LB & 0.398 & 0.159 & 0.202 & 97.051 & 1 & 514 & $0.000^{*}$ \\
\hline OHI --> WE (Direct effect) & 0.375 & 0.141 & 0.340 & 84.306 & 1 & 514 & $0.000^{*}$ \\
\hline OHI--> LB --> WE (Indirect effect) & 0.466 & 0.217 & 0.310 & 71.027 & 2 & 513 & $0.000^{*}$ \\
\hline
\end{tabular}

* - significant at the 0.05 level

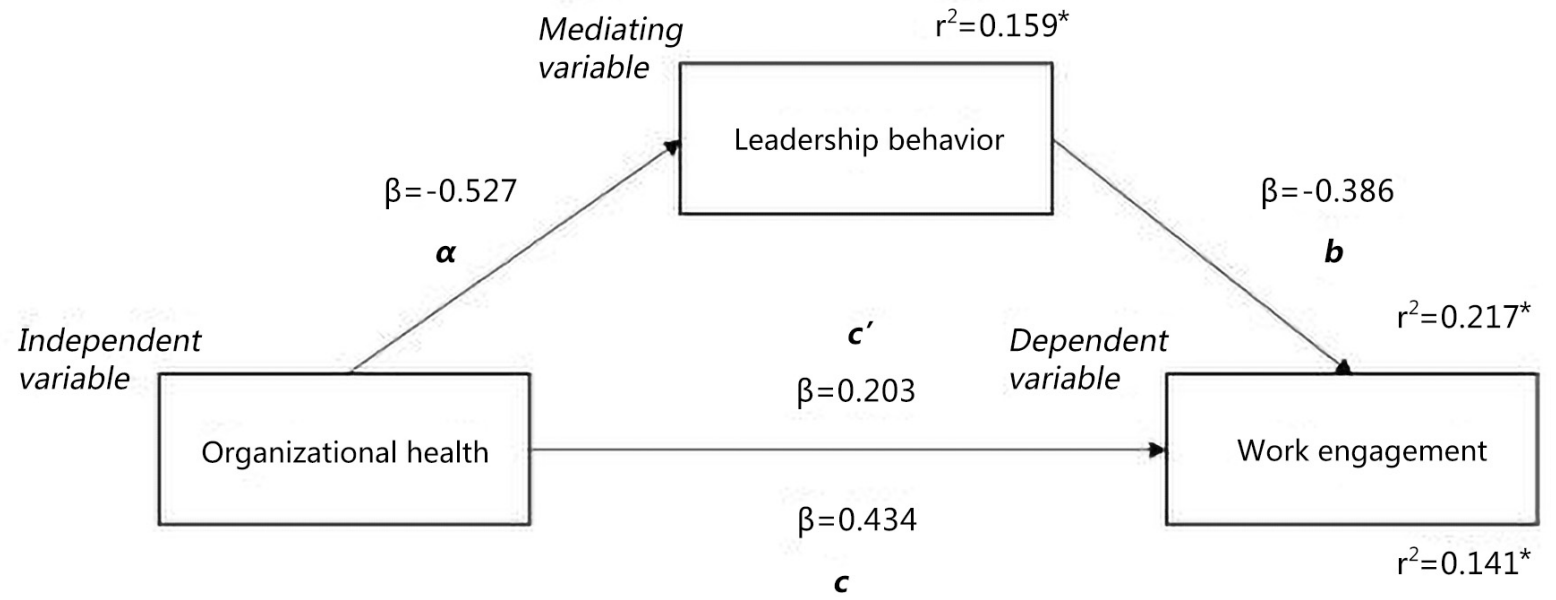

Figure 1. Mediating effects of Leadership behaviour

The $\beta$ estimates from the structural path coefficients as well as the R2 values that suggest the power of explanation of independent variables on the dependent variables are depicted in Figure 1.

\section{Discussion}

In this study, we examined the role of the principal's leadership behaviour in mediating the effects of organizational health on work engagement. Firstly, Organizational health was found to have a significant influence on the work engagement of teachers. The result shows that teacher's vigor, dedication, and absorption in work increase as their schools become healthier. This supports the stance put forward by previous studies like Song, Kim, Chai, and Bae (2014); Klusmann, Kunter, Trautwein, Lüdtke, et al. (2008); and Bakker, Hakanen, Demerouti, and Xanthopoulou (2007) which reported that job resources and school climate predicted work engagement of teachers. Organizational health was found to have a significant impact on the leadership behavior of principals (both Consideration and Initiating structure). This indicates that positive school health enables its principals to be more considerate towards other teachers' opinions (Consideration behavior) and effectively define their roles and those of their subordinates in achieving organizational goals (Initiating behavior).

Moreover, previous studies like Fernet, Guay, Senécal and Austin (2012), Eyal and Roth (2011), and Griffith (2004) established empirical relationships between the principal's leadership style and teacher's job outcomes work engagement, motivation, commitment, and employee turnover. With these findings, the current study also identified that the leadership behaviour of principals (Consideration and Initiating structure) has a significant impact on the work engagement of teachers. Principals who can direct the activities of their group towards 
achieving their goals and maintain their group as a single cohesive unit were found to influence the teachers to become highly engaged with their work. Also, principals who were considered to respect the opinions of their subordinates can positively affect the work engagement of teachers. Teachers who realize that their opinions and ideas are being considered by their superiors tend to get more involved in their work which in turn will enhance their work engagement levels.

Most importantly, the study observed that such leadership behaviour of principals (Initiating structure and Consideration) partially mediated this relationship between organizational health and work engagement of teachers, which has not been explored previously.

\section{Implications and Recommendations}

The results indicate that teacher's work engagement was uniquely related to organizational health which reflects schools' attitudes towards educating students and promoting internal norms and values for student achievement at institutional, managerial and technical levels. Hence, developing interventions that can sustain and support organizational health toward educating students and promoting internal values can enhance the work engagement of teachers. For example, implementation of Positive Behavioral Interventions and Supports can promote organizational health which in turn enhances work engagement in teachers. Further, the results indicate that the work engagement of teachers is affected by the Consideration and Initiating behavior of principals. Hence, principals as leaders must play an active role in directing their subordinates through appropriate planning and communication of information so that teachers will be more encouraged at their work. Further, by ensuring a climate of good rapport with teachers and two-way communication, principals can increase the engagement of teachers.

\section{Scope, Limitations and Future Directions}

The current study was limited only to secondary school teachers in the city of Bangalore. The factors such as principal consideration and initiating behaviour were measured indirectly through the perceptions of teachers using the research instrument. In the future, the study can be expanded by including assistant principals to measure their leadership behaviour directly and gain deep insights on their mediating influence between organizational health and work engagement. Further, organizational health was measured only at an individual level in the study; however, it was examined at a school level to gain a comprehensive understanding of its impact on work engagement on teachers.

\section{Conclusions}

The present study found evidence for the mediating influence of the principal's leadership behaviour on the relationship between organizational health and work engagement of teachers. However, only partial mediating effects could be observed. Hence, it can be understood that the involvement of teachers in their work cannot be completely attributed to either the health of the school alone or the leadership behaviour of school leaders or administrators like principals.

\section{REFERENCES}

[1] Albrecht, S. L. (2010). Employee engagement: 10 key questions for research and practice. Handbook of employ ee engagement: Perspectives, issues, research and practice, 3-19.

[2] Aldridge, J. M., \& Fraser, B. J. (2016). Teachers' views of their school climate and its relationship with teacher self-efficacy and job satisfaction. Learning Environments Research, 19(2), 291-307.

[3] Allen, N., Grigsby, B., \& Peters, M. L. (2015). Does Leadership Matter? Examining the Relationship among Transformational Leadership, School Climate, and Student Achievement. International Journal of Educational Leadership Preparation, 10(2), 1-22.

[4] Bakker, A. B. (2011). An evidence-based model of work engagement. Current directions in psychological science, 20(4), 265-269.

[5] Bakker, A. B., Hakanen, J. J., Demerouti, E., \& Xanthopoulou, D. (2007). Job resources boost work engagement, particularly when job demands are high. Journal of educational psychology, 99(2), 274.

[6] Bakker, A. B., Schaufeli, W. B., Leiter, M. P., \& Taris, T. W. (2008). Work engagement: An emerging concept in occupational health psychology. Work \& stress, 22(3), 187-200.

[7] Buluc, B. (2015). Relationship between instructional leadership and organizational health in primary schools. The Anthropologist, 19(1), 175-183.

[8] Dou, D., Devos, G., \& Valcke, M. (2017). The relationships between school autonomy gap, principal leadership, teachers' job satisfaction and organizational commitment. Educational Management Administration \& Leadership, 45(6), 959-977.

[9] Evenson, W. L. (1959). Leadership behaviour of high school principals. The bulletin of the National Association of Secondary School Principals, 43(248), 96-101.

[10] Eyal, O., \& Roth, G. (2011). Principals' leadership and teachers' motivation: Self-determination theory analysis. 
Journal of Educational Administration, 49(3), 256-275.

[11] Fernet, C., Guay, F., Senécal, C., \& Austin, S. (2012). Predicting intraindividual changes in teacher burnout: The role of perceived school environment and motivational factors. Teaching and teacher education, 28(4), 514-525.

[12] Fernet, C., Trépanier, S. G., Austin, S., \& Levesque-Côté, J. (2016). Committed, inspiring, and healthy teachers: How do school environment and motivational factors facilitate optimal functioning at career start? Teaching and Teacher Education, 59, 481-491.

[13] Freiberg, H. J. (2005). School climate: Measuring, improving and sustaining healthy learning environments. Routledge.

[14] Garcia, R. P. (2018). The relationship between transformational leadership and organizational school climate as perceived by teachers in the Philippines (Doctoral dissertation, St. John's University (New York), School of Education and Human Services).

[15] Griffith, J. (2004). Relation of principal transformational leadership to school staff job satisfaction, staff turnover, and school performance. Journal of educational administration, 42(3), 333-356.

[16] Guglielmi, D., Bruni, I., Simbula, S., Fraccaroli, F., \& Depolo, M. (2016). What drives teacher engagement: A study of different age cohorts. European Journal of Psychology of Education, 31(3), 323-340.

[17] Hakanen, J. J., Bakker, A. B., \& Schaufeli, W. B. (2006). Burnout and work engagement among teachers. Journal of school psychology, 43(6), 495-513.

[18] Hakanen, J. J., Perhoniemi, R., \& Toppinen-Tanner, S. (2008). Positive gain spirals at work: From job resources to work engagement, personal initiative and work-unit innovativeness. Journal of vocational behaviour, 73(1), 78-91.

[19] Halpin, A. W. (1956). The behaviour of leaders. Educational Leadership, 14(3), 172-186.

[20] Halpin, A. W., \& Winer, B. J. (1957). A factorial study of the leader behaviour descriptions. Leader behaviour: Its description and measurement, 39-51.

[21] Hobfoll, S. E., Johnson, R. J., Ennis, N., \& Jackson, A. P. (2003). Resource loss, resource gain, and emotional outcomes among inner city women. Journal of personality and social psychology, 84(3), 632 .

[22] Hoy, W. K., \& Fedman, J. A. (1987). Organizational health: The concept and its measure. Journal of research and Development in Education, 20(4), 30-37.

[23] Hoy, W. K., \& Tarter, C. J. (1997). The road to open and healthy schools: A handbook for change. Thousand Oaks, CA: Corwin Press.

[24] Hoy, W. K., \& Woolfolk, A. E. (1993). Teachers' sense of efficacy and the organizational health of schools. The elementary school journal, 93(4), 355-372.

[25] Hoy, W. K., Tarter, C. J., \& Bliss, J. R. (1990). Organizational climate, school health, and effectiveness: A comparative analysis. Educational Administration Quarterly, 26(3), 260-279.
[26] Hoy, W. K., Tarter, C. J., \& Kottkamp, R. B. (1991). Open schools, healthy schools: Measuring organizational climate. Corwin Press.

[27] Kahn, W. A. (1990). Psychological conditions of personal engagement and disengagement at work. Academy of management journal, 33(4), 692-724.

[28] Klusmann, U., Kunter, M., Trautwein, U., Lüdtke, O., \& Baumert, J. (2008). Engagement and emotional exhaustion in teachers: Does the school context make a difference? Applied Psychology, 57, 127-151.

[29] Korkmaz, M. (2007). The effects of leadership styles on organizational health. Educational Research Quarterly, 30(3), 23-55.

[30] Kunz, D. W., \& Hoy, W. K. (1976). Leadership style of principals and the professional zone of acceptance of teachers. Educational Administration Quarterly, 12(3), 49-64.

[31] Miles, M. B. (1969). Planned change and organizational health: Figure and ground. Organizations and human behaviour, 375-391.

[32] Muijs, D., \& Harris, A. (2006). Teacher led school improvement: Teacher leadership in the UK. Teaching and teacher education, 22(8), 961-972.

[33] Nazir, O., \& Islam, J. U. (2017). Enhancing organizational commitment and employee performance throu gh employee engagement: An empirical check. South Asian Journal of Business Studies, 6(1), 98-114.

[34] Roslan, N. A., Ho, J. A., Ng, S. I., \& Sambasivan, M. (2015). Job demands \& job resources: Predicting burnout and work engagement among teachers. International Proceedings of Economics Development and Research, 84, 138-145.

[35] Savas, A. C., \& Karakus, M. (2012). The Relationships between School Organizational Health and Teachers' In-Role and Extra-Role Behaviours. International Journal of Social Sciences \& Education, 3(1).

[36] Schaufeli, W. B., \& Bakker, A. B. (2003). Utrecht work engagement scale: Preliminary manual. Occupational Health Psy chology Unit, Utrecht University, Utrecht, 26.

[37] Schaufeli, W. B., \& Bakker, A. B. (2004). Job demands, job resources, and their relationship with burnout and engagement: A multi-sample study. Journal of Organizational Behaviour: The International Journal of Industrial, Occupational and Organizational Psychology and Behaviour, 25(3), 293-315.

[38] Schaufeli, W. B., Bakker, A. B., \& Van Rhenen, W. (2009). How changes in job demands and resources predict burnout, work engagement, and sickness absenteeism. Journal of Organizational Behaviour: The International Journal of Industrial, Occupational and Organizational Psychology and Behaviour, 30(7), 893-917.

[39] Schaufeli, W., Salanova, M., Gonzalez-Roma, V., \& Bakker, A. (2002). The measurement of burnout and engagement: A confirmatory factor analytic approach 'Journal of Happiness Studies.

[40] Song, J. H., Kim, W., Chai, D. S., \& Bae, S. H. (2014). The impact of an innovative school climate on teachers' knowledge creation activities in Korean schools: The 
mediating role of teachers' knowledge sharing and work engagement. KEDI Journal of Educational Policy, 11(2).

[41] Stolp, S. W. (1994). Leadership for school culture.

[42] Storm, K., \& Rothmann, S. (2003). A p sychometric analy sis of the Utrecht Work Engagement Scale in the South African police service. SA Journal of Industrial Psychology, 29(4), 62-70.

[43] van Beek, I., Hu, Q., Schaufeli, W. B., Taris, T. W., \& Schreurs, B. H. (2012). For fun, love, or money: What drives workaholic, en gaged, and burned-out employees at work? Applied Psy chology, 61(1), 30-55.

[44] Wang, X., Liu, L., Zou, F., Hao, J., \& Wu, H. (2017). Associations of occupational stressors, perceived organizational support, and psy chological capital with work engagement among Chinese female nurses. BioMed research international, 2017.

[45] Xanthopoulou, D., Bakker, A. B., Demerouti, E., \& Kantas, A. (2007). The measurement of burnout and engagement: A cross-cultural study comparing Greece and the Netherlands. New Review of Social Psychology, 7(2), 40-52.

[46] Yi-wen, Z., \& Yi-qun, C. (2005). The Chinese version of Utrecht Work Engagement Scale: An examination of reliability and validity. Chinese Journal of Clinical Psychology. 